\title{
The Practical Consequences for Insurers of the Freedom of Services throughout the European Community
}

\author{
by Prof. Dr. jur. Dr.-Ing. E. h. Reimer Schmidt*
}

1. This lecture is not intended as a contribution to the law-making of the European Community (EC). I am not speaking de lege ferenda but about how industry practice will cope with what has been created or proposed in this area to date. While attempting to stand clear of the conflict of interests that every law-making process necessarily involves, my concern in this lecture is to counteract the erroneous impression that the insurance industry in the member states is not considering the practical problems of the single market.

I wonder, moreover, whether much of the current debate about insurance is not a little too theoretical. The fact that the industry's services are of a complex kind - typical of an advanced economy - and are "invisible" has always led to varied analyses and explanations of the purpose and function of insurance. Recently, however, the discussion has become very intense, if one thinks of the call from the other side of the English Channel for the insurance industry (i.e. that country's insurance industry) to wake up, or of the diverse considerations on the subject of " 1990 as the insurance industry's target year", to quote a headline of the Zürcher Zeitung. In addition, there is the peculiarity of the EC's lawmaking method, its use of guidelines procedures which create, so to say, "annual rings" of legislation. The law-making bodies of the EC and member states - the latter when incorporating legislation into national law - have to return again and again to the same issues, almost annually, and are constantly coming up with new and sometimes doctrinaire ideas, which severely test a nation's sense of justice and at times call into question the willingness of market members to obey the law. In any case, the extent to which member states are willing to obey the law does vary. It is only right and necessary that objective operating opportunities in other countries and subjective patterns of evaluation should be discussed inside and outside EC member states; indeed liberalisation has had the stimulative effect of triggering off a form of verbal actionism. The implications of deregulation, a concept which was developed particularly in the USA, are in this connection far-reaching. Deregulation stimulates the initiative of entrepreneurs by reducing the structure of governmental protective regulations; some are the result of transient, short-term pressures while others are the legacy of centuries of trading. To some extent also deregulation runs counter to the idea of consumer protection. In any case, the need for re-regulation becomes immediately apparent the moment damage threatens or has actually occurred in any sector where technical,

\footnotetext{
* President of the Geneva Association
} 
medical, financial or purely legal protective regulations have been dismantled. In order to prevent this, a reduction in the somewhat coarser network of protective regulations is frequently accompanied by the creation of a fine and closer-meshed system.

To complete my introduction, I would like to add one more comment. Throughout this lecture equal account will be taken of "neighbourhoods under international law" (Switzerland, Austria, Eastern European countries) and of supranational agreements and institutions, and in particular GATT, UN/UNCTAD and (as far as the Federal Republic of Germany is concerned) USA (and the special relationship with the German Democratic Republic). In short, analysis and differentiation of the repercussions is almost as important for us as for the above-mentioned countries.

The ideas I am presenting today are being thoroughly considered by the industry's own critics and the private insurance industry is by no means unaware of them. It is just that its external image does not completely match the ideas on trading that have been developed, particularly recently, in the field of theoretical national economics by so many of those who believe in the theory of competition repressing the concept of ordo-liberalism. Therefore, it is my concern in this lecture to highlight the practical prospects.

After more than 33 years in practical primary insurance and re-insurance neither am I speaking, incidentally, on behalf of any associations or market segments. And I venture to hope that even my academic training has not weakened my grasp of the practicalities involved.

Before I deal with the understandably critical reaction to what member states may be faced with in the shape of a Common Insurance Market, I must first say that the Treaty of Rome, through its tremendous liberalizing effect - which provided a cultural basis for the expansion of the German economic miracle - has greatly helped to stimulate the initiative of member states in their national economies.

It is interesting to note that within the framework of the general contractual objectives of the EEC Treaty, in addition, that is, to customs union, harmonization and liberalization, each of the six founder members pursued important, quite practical goals when joining the economic union. The French were very keen on satisfying their farming industry. I need not consider here whether and to what extent the systems we are burdened with today conformed or indeed still conform with the Treaty. The Germans were thinking primarily of a free market for industrial products. The Italians had in mind above all the "export" of labour, which was subsequently to prove so uncommonly successful. The three smaller partners in the first stage of the EC - the Netherlands, Belgium, Luxembourg - saw themselves as the vehicle of the Community's trade and financial policy.

The accessions of the other members - also six in number - were clearly regarded by the rest of the Community as "rocket stages" of liberalization. Yet only partially did they have this effect, although the entry of Great Britain introduced significant new trends in those industries in which their strength lay: banking, shipping, air transport and insurance. Spain's entry relatively soon after the end of the dictatorship generated an economic stimulus which had previously been thought virtually impossible. Here I can only refer in passing to the "dilution problems" that the entry of further states could present. However, I feel obliged to make a brief, basically positive, interim observation, because pictures without a background frequently lack perspective. 
2. This lecture is concerned primarily with practical objectives in a situation where liberalisation and deregulation have detonated an explosion of financial services. But there is one theoretical idea I feel I must mention: freedom of establishment has been stimulated by the freedom to choose one's location of production. Freedom to provide services throughout the $\mathrm{EC}$ is intended to make it possible to exploit the local advantages of production vis-à-vis the customers of other sectors. In both cases the trade barriers contained in the legal framework conditions should be reduced as far as possible by harmonizing laws. But because the competitors' influence over local conditions, especially tax law and social legislation, is limited, the scope for ideal economic optimization is also rather small. Were I able to do so, I should be the first to advance the theory that the market will shortly be forcing tax rates to adjust. National legislators, however, are simply not prepared substantially to reduce local disadvantages for their own companies if this means compromising the budget and diminishing social legislation. The automatism of the model, therefore, causes far greater difficulties in practice than in theory. In this respect the efforts of the EC Commission to achieve harmonization have, of course, been duly recognized. Yet - however much one approves of the objectives of the EEC Treaty - harmonization has its limits, particularly because of differences in legal culture, sense of justice and the extent to which member states are prepared to comply with the law.

When we come to the field of practical insurance business, we can see, first, that the abolition of restrictions on freedom of establishment has, in principle, occurred in a way that reflects the realities of the insurance industry and that has led to greater integration of markets. Account was taken of the psychological realities of bulk business by subjecting branches to the law of the country in which they operate - a rule which the European Court of Justice is known to have violated in some cases in applying EC antitrust law. These realities surface most clearly in the advertising slogan "The representative lives next door". But market practices were not fundamentally "changed in a European way" by the freedom of establishment insurance companies were granted. Perhaps one or two aspects of the regulations governing freedom of establishment still need to be altered, but there are limits to what legislators can do here. An effective change has been made.

I do not wish to appear a know-all by attempting to answer today questions about the impact of EC regulations on non-member states, and in particular I shall refrain from making comments on economic policy. After all, the OECD is still with us, and the GATT is doing something about services, something positive I hope. In my view, non-member country solutions based on independent national legislation take precedence - as a matter of principle - over law-making through treaties under international law. To date predominant public opinion in other non-member states also appears to be moving in this direction, e.g. in Norway, Finland and Turkey. I believe that adaption of one's own legislation (within the framework of what is possible and desirable) i.e. arbitrary adaption, is more effective because formal adoption of Common Market law in a given area can only ever be a "snapshot" of the on-going development process and I think that the formal adoption of further provisions - i. e. automatic adaptation - causes major new difficulties. Of course, in this case one cannot avoid the problem of reciprocity. Political solutions would perhaps involve granting limited and, in some instances, more symbolic reciprocity given the size and output ratios of one's own internal market compared to those of the EC. The reports currently appearing in the Neue Zürcher Zeitung on the subject of Switzerland and the EC are particularly noteworthy in this respect. 
Of course, the independent subsidiaries of non-EEC parent companies have not been covered at all by the regulations in force up to date, so that difficulties unrelated to insurance supervisory law can still play a part. As a "quartum comparationis" in addition to establishment, services and subsidiaries, the European limited company of the second "intellectual impression" is now being discussed; it operates under EC law, and its branches outside the EC and their services are treated like those of the operating-country companies, so that they consititue, so to speak, a direct route to the whole of EC Europe. This new conception is likely to find favour in particular with the British and German governments. But at the same time this model could also mean a structural restriction on competition for all other forms of company, so that the speaker has considerable misgivings about a European company of this kind, although in certain circumstances it renders superflous the formation of clusters of national subsidiaries.

In this connection it must be said that the preservation of market structures (large, medium and small companies) is of far greater importance than has been conceded hitherto. Incidentally, the problem of the formation of group controlling companies has, as far as I am aware, not been resolved for mutual insurance associations, with one limited exception in France, if, that is, one disregards the option of the mutual association itself as the parent of limited companies. Furthermore, the idea that large risks should be covered by large companies, medium-sized risks by medium-sized companies and small risks by small companies is irrelevant. Re-insurers especially should be interested in this question. To suggest that insurance requirements can best be covered by insurance oligopolies is true only in theory. They would merely be the predecessors of uniform state companies. In this context I would like to make one last comment on freedom of establishment, which I risk even in the circumstance of deregulation I have already mentioned. One advantage of the freedom of establishment system is that it allows for easier supervision of insurance business according to uniform principles of domestic and foreign companies and for all forms of distribution. In part this also means market transparency and comparability of prices with price competition. In addition, freedom of establishment meets the need of policy-holders for security in many - but not all - countries by having a local insurance representative. But freedom of establishment does not mean'a uniform market with broad model competition.

3. The insurance industry had probably not expected the thunderbolt with which the European Court of Justice with its four rulings of 4 December 1986 broke new ground for the abolition of restrictions on freedom of services; at least the industry had not expected a "practical thunderbolt" if it may be thus expressed. The view had been held for years that different degrees of supervision were required for bulk and wholesale business because of their different nature per se, even on an interpretation of current supervisory law. The different regulations governing bulk and wholesale business reflect a compromise between consumer protection in the narrower sense, i. e. "consumer protection by regulation" and general "protection of the policy-holder by competition". In accordance with the philosophy of those who implemented the Treaty of Rome, consumer protection by regulation has been granted provisional status only.

It is not my intention to return here to the issue of treshold values, although it must be pointed out that in practical business it is probably not always certain that limits will be observed, and monitoring by supervisory authorities is particularly difficult. Here, the problem of pluralism - as I shall call it - of freedom of services becomes apparent. Creative pluralism becomes a problem when matters are taken to real extremes. 
But this is only the tip of the iceberg of practical problems presented by an activity which Dr. Walter Diehl described as the activity of the "absentee insurer". The highly influential theory of competition fails to recognize that, for example, not only are advertising and the conclusion of contracts relevant to competition but also and above all the actual provision of the insurance service. Consumers, just like bulk purchasers of insurance cover, know how the insurer behaves in the event of claims or expiry and judge him accordingly. The regulatory model which was adopted after the introduction of the principle of majority voting in the Council of Ministers is clearly of logical significance for free service businesses. But whether the model is sufficiently inexpensive to be attractive and whether it leaves sufficient customer-friendly regulatory options for the settlement of claims are open questions. The criticism that the model solely or primarily takes account of insurance brokers' interest is clearly exaggerated. Logically, of course, one can raise the dialectical objection that the broker is necessary in the theoretical model if one wants to avoid simulating an insurance purchaser who is generally able and willing to secure information, and who can compare both prices and products. The question of the finder's cost can then, easily be disregarded. Even economic magazines do not fill the gap completely. In any case, brokers with the necessary competence do not exist in sufficent numbers in all the member states. In this connection, the continuing process of concentration in the brokerage sector needs to be watched. Experience with insurance companies engaged in direct selling, particularly in the life assurance area, shows that, as is generally known, the markets of insurance prospects who are "discriminating" in this area are not very large at present. More will have to be said about the information problem in the future.

I have just mentioned insurance brokers, who have an essential function in the model as "search assistants" to the insurance consumer. In an increasingly dense market the sale of insurance - called distribution by the company - is assuming an even more essential role than in the past. The view - albeit only sporadically held - that distribution as such would become cheaper given greater supply, contains a fundamental flaw. In the speaker's view, distribution costs will tend to rise rather than fall because of the key position of the distribution bodies. It is to be hoped that hybrids combining brokers as the insurance purchaser's "search assistants" and agents as the insurer's "distribution assistants", so-called brokeragents, will become even rarer than they are today. As we know, in Great Britain they are illegal under the Financial Services Act. In a wider sense this also covers cases in which brokers are openly or covertly controlled by insurance companies.

I will leave open the question as to whether the holding of special examinations to test their professional knowledge would be useful to brokers as a special group of intermediaries; experience in the Netherlands has proved positive. In the Federal Republic of Germany efforts are being made to set up a general system of vocational training for insurance intermediaries. If one considers the high degree of technicality not only of so-called technical but also of industrial risks in general, and if one also takes into account the importance of risk prevention in the context of risk management, the extension of the brokerage market, even in this area, means a further dilution of the immediate contact between the insurer and the policy-holder for these major risks. The idea that this trend constitutes an imposition is worth looking at more carefully for it suggests that we should be seeking even more effective means of risk managment that at the underwriting level. The broker needs to be more heavily committed in the field of loss prevention; for he lacks the policy-holder's 
self-interest in replacing loss prevention investments by financial provision over time, as also the insurer's self-interest in keeping expenditure as low as possible in the event of claims.

These arguments, which reflect the necessities of practice, extend to the so-called cumulation problem. The ban on cumulation means in principle that an EC insurer who maintains a permanent presence as an actual branch or representation on agency lines in a member state must also formally set up a branch. This also applies if an office is managed by only one person, even though that person may be independent but under instruction to act as an agency for the insurance company. Whoever has set up a branch must, as a matter of principle, transact his business in that country through this branch. Neither is he allowed complete freedom of services (cumulation is not permitted). Varying degrees of stringency for the ban on cumulation are conceivable. We are not concerned with exceptions here. It is, however, not convincing to use a restrictive interpretation of the concept of "agency" to reach solutions which weaken the ban on cumulation. The theory criticized here is: "An agent is not yet automatically an agency". This is undoubtly a weakness of the whole regulatory model, as is observance of the ban. We might also be faced with the problem of cumulation, which was dealt with from the viewpoint of the European Court of Justice in the Second Coordinating Directive on Claims, in connection, inter alia, with the harmonization of motor-vehicle owners' compulsory third-party insurance.

Does an office that operates loss prevention in respect of the risks assumed by way of free services constitute a factual situation which gives rise to the need for establishing a branch or which embodies the inadmissible dualtrack approach? The same question also arises in respect of claim settlement offices which, according to the insurer's guidelines, settle claims more or less independently or, if the need arises, seek instructions. They are known to have come into being under the EC directive on legal protection insurance as a legal means of preventing collusion. The question here is: Should loss prevention offices which work for more than one insurer (more than one group) be judged differently from commercial agent settlement offices? In addition, under German insurance supervisory law, the question arises as to whether or not this constitutes hiving off a function - a circumstance which is relevant to supervisory law - that assigns claim settlement as an essential activity to the insurer. Finally, problems of antitrust law under paragraph 85 of the EEC Treaty might arise in the case of settlement offices run by several insurers. Two questions arise here: does a branch of an insurance broker who mediates as the insurance purchaser's "search assistant" but who holds a claim settlement authorization from the insurer, constitute a branch of the insurer? How should the so-called technical broker who also signs the documents by power of attorney from the insurer by judged? Insurance brokers naturally take the view that they are not insurance branches. Doubt persist.

For business practice it will above all depend on how the Second Coordinating Directive on Claims is incorporated into national laws, especially how the member states' voting rights granted in connection with the DLF are used.

4. Coordination - in this context of service opportunities - and deregulation, i. e. liberalization, are among the fundamental objectives of the Treaty of Rome. Both in the theoretical model and from a purely practical point of view, the consequence of liberalization and the withdrawal of the state from the legal framework conditions for economic activity is always that the conditions of competition are reviewed and normally aggravated. The aim is to prevent substitution of government regulation by cartels and to counter any extension 
of unfair competition. Conduct that complies with good business practice is usually more accurately defined.

This is precisely what is happening in the current stage of development of the Common Market, whereby - as I said earlier - no one is waiting for 1992 for things to begin to happen. Antitrust law, which, according to a decision of the European Court of Justice of February 1987 , is also applicable to companies with their registered office in a non-member state, is faced with a rather special problem regarding the relationship between EC law and national law. This lecture is not about insurance antitrust law. But attention must be drawn to the interdependence of the regulatory provisions of the General Insurance Conditions, that is, approval and supervision on the one hand and the evaluation of insurance conditions under antitrust law on the other. Here, theoreticians of economic competition emphatically take the view that the protective function of government-determined framework conditions is to a large extent taken over by competition. Here too, therefore, the prevailing opinion is that the empty space created by deregulation should not be "allowed to fall into the hands of cartels" if I may use such an expression. Here too, old practioners doubt that the market's self-healing powers will extend to every nook and cranny of the small print or that brokers will perform a protective function in the consumer's interest with regard to General Insurance Conditions in bulk business. Therefore they advocate exhausting the possibilities opened up in the Second Coordinating Directive for bulk business, namely those of maintaining or re-introducing approval of conditions. The request for group exemption under EC antitrust law include, in addition to treaty re-insurance and co-insurance, in particular the General Insurance Conditions. The member states' protective systems are not equivalent in respect of the General Insurance Conditions. If freedom to choose the law by which one wishes to be bound has been granted, such law can also be evaded. Concerning the relationship between EC antitrust law and national regulations prohibiting restrictions on competition, it suffices to point our that what is at issue here is the absolute or merely relative preeminence of EC law. The domestic segments of the Common Internal Market will apparently continue to be governed by national antitrust laws, whose varying nature will determine to what extent the trade business they inevitably constitute are visible.

"Merger supervision", as it is called, occupies a special place within the legal regulations governing competition. Company mergers will come up against legal barriers if they have the potential to dominate a market and are seen to be attempting to do so. The regulation model provides in principle for government control ex ante, i. e. the requirement of government approval, whose form may vary enormously. As such, this constitute a barrier to market entry for large companies in the event of creation by a legal act, i. e. the license is made harder to obtain. Because large companies can, on the one hand, be instruments of individual governments' industrial policy (i. e. interventionist policy to promote the national economy), but, on the other, be criticised for restricting competition in the single internal market. The criterion of what constitutes the public interest is here of great importance.

Another point that springs to mind is that "critical size" means different things, depending on whether one is speaking of the national market segment, the EC internal market or even the world market. Future EC regulation not only sets an extremely interesting task, but also entails legislative decision of utmost importance for the companies of member states and thus also for the national economies. Of relevance here is the conclusion not only that the "managing" state itself maintains and has recently created large companies but that the mechanism of friendly and hostile company takeovers raises the pointed 
question of exactly where freedom is being abused by an individual takeover, in addition to the question of market domination that has to be examined in all company takeovers. One final remark on competition rules, which will have to be enshrined in Community law when there is a Common Market: to date the concept of dumping has not really been satisfactorily defined for insurance business. Where do we draw the line in terms of what is permissible if high losses are reckoned as an acceptable price for penetrating a market by undercutting?

5. Closely connected with the complex series of issues just discussed is the freedom already granted in the case of wholesale business to choose the law by which a company will be bound, i. e. the option open to contracting parties to choose freely the applicable national law with regard to the individual insurance policy. Thus the idea developed in international private law (rules governing the conflict of laws), whereby it is primarily the will of the parties that determines the applicable law governing a contract, is applied in practice. It is easy to predict how practice will develop. Above all, it becomes difficult to define the non-amendable binding national law. The broker and the insurer will influence practical regulations. But granting freedom to choose the applicable law also constitutes a remedy, primarily motivated by logic, designed to avoid cases of discrimination despite a lack of coordination of insurance contract laws. Here too I would not criticize the level of coordination, I am merely describing it. The sentence "volenti non fit iniuria" applies here, meaning in concrete terms: "Whoever has chosen his own applicable law cannot be discriminated against".

Allow me at this point to degress briefly: it is known that the additional risk in implementation of law is very great when one chooses a foreign legal system. The normal risk is greatly increased. Therefore I believe that in future arbitration agreements, i. e. contractual agreements to the effect that any legal dispute is to be settled by an arbitration court, will also be particularly important in connection with suits filed against insurers for payment. There are tried and tested procedures and procedural aids which deserve consideration; that is, arbitration procedures that extend beyond common ones.

6. One fundamental element is still lacking in this comprehensive argument. As you are aware, the starting point for the creation of the insurance supervisory authority is the idea of protecting the policy-holder as the creditor of the insurance benefit, which frequently has to be provided over a long period of time. The supervisory authorities may accordingly have included the idea of protection against debtors mainly under the influence of the consumer protection movement. If protection of creditors is abolished or reduced by deregulation, the question of "replacement supervision" arises. Now that the idea of compulsory re-insurance has been abandoned - and rightly so - as unsuited to a liberal market, the solution is thought to have been found in bankruptcy protection funds, i. e. a collective guarantee by the industry or its sub-sectors. Such funds, known to exist particularly in the USA, are highly controversial in the insurance industry because "properly-managed" companies would not only have to assume liability for the "unlucky ones" but above all for the "badlymanaged" companies. In this connection questions arise as to the funds' influence on business practices, that is, as to the funds' supervisory powers. They then replace not only the state's protective function but also its intervention function.

7. It remains for me to make some concluding comments. In this lecture the speaker has deliberately avoided interfering with proposals in law-making processes that are currently 
in full swing. Even a general description of the legal problems would be going too far. As I said above, I am concerned with the importance of regulations for insurance practice.

This practice above all includes life insurance, for which a Second Coordinating Directive is being prepared, systematically based on the corresponding casualty insurance directive. Consideration is being given to whether and, in certain cases, in what sectors it is possible to implement the principle of the country of incorporation, i. e. supervision by the authority of the country of incorporation. A simple distinction between bulk and wholesale business is for the life insurer not available. The only correct approach here is surely to disregard segregation of so-called wholesale business, which would be subjected to the country of incorporation principle. For threshold values as a criterion are clearly unsuitable in this case. But even group insurances do not extend beyond the sphere of protection characteristic of mass risks; for in the vast majority of cases it is mass risks grouped together for reasons of rationalization that policy-holders need to be protected against. Questions also arise about the concept of establishment in connection with the top of the group. It is interesting that brokers are currently placing advertisements in the group insurance sector. Here again attention must be drawn to the unsolved question of harmonization of tax systems.

Of considerable importance for life assurance is the directive on capital movements of June 1988, removing restrictions. Thus the transfer of premiums and services of life insurance has been formally liberalized. What is important is the catalogue of definitions, known as the nomenclature of capital movements which is appended to the directive.

And now I too have uttered the catchphrase "combined financial services", about which much has been said and written in our countries. Like Pierre Moussa, who recently addressed the CEA, I believe that the control of insurance companies by banks and, vice versa, the control of banks by insurance companies should be avoided. It appears to be more attractive to build up a financial holding company to control both. The combination of distribution channels and the creation of corresponding products play a major role.

At the end of this lecture you will probably ask me for my opinion on the EC national sub-markets once the law-making measures in hand have been implemented. Will there be practical service transactions without national branches to any appreciable extent? First of all, I believe that for wholesale business, which, as is known, is handled in two stages, this form of distribution will become the norm. It could, of course, turn out that the details of the regulations may prove too complicated, so that the customers might be frightened off. On the other hand, the customers, initially drawn by the charms of pure service transactions, might return after a certain period of time has elapsed. The trend will depend on the size of the risks, the practical possibility for industrial groups to have a really transparent comprehensive cover on a DLF basis, on pricing and insurers' settlement practices, as also on the function of brokers. In view of this, I believe there will be movement but no earthshattering upheavals.

I take a different view of bulk business. If one places too much strain here on the idea of the pure service transaction, one damages the whole basis of trust in the insurance business. In my opinion, the average person in the street will in the end simply feel more comfortable with his or her current insurer. In this respect the above-mentioned question of the General Insurance Conditions plays an important part, as does actual practice in the courts. Yet such forecasts are most unreliable, especially if they go beyond the next few 
years. And contrary to theoretical economics which assumes that the consumer acts rationally, in the mass market where mass psychology prevails irrational acts are the norm.

Finally, for the sake of completeness I must broach the issue of so-called home-foreign insurance policies. But these are not only offers in letter form or transmitted by electric or electronic media on the sole initiative of the applicant to be insured, but mainly policies taken out personally. The theory is that a person who deliberately renounces his country's protection in the manner described shall not be granted such protection. There is a whole host of additional questions: thus, as far as I know, at present home-foreign insurance by correspondence in the EC exists only under German supervisory law, namely in a narrowly defined factual sitation. What jurisdiction, one must ask, will apply to insurance policies which grant legal claims against the insurer to third parties who, for their part, have not moved out of the protective sphere of their law? Can the insurance purchaser "diminish" his legal position on conclusion of the policy? The provision of national laws which lay down the insurance obligations - and they are very numerous - probably preclude home-foreign insurance policies. Finally, the basic view is that no home-foreign insurance policy is permitted when the policy has been concluded as a result of advertising by the insurer or with the participation of national intermediaries.

The development of the Single Internal Market is now obviously proceeding very rapidly. As far as future developments are concerned, it is roughly possible to predict the way wholesale business will be handled. A lightly larger share of national industrial-insurance portfolios will move to other member states. There traffic will be two-way. It may be assumed that insurance companies which are renowned as industrial insurers will continue to have substantial national portfolios. In my opinion the following will apply: "The established insurer has priority over the absentee". Regarding bulk business, it is to be hoped that we will not have to wait for collapses and other scandals to restore credence to the conviction that particularly in those areas where third parties are co-affected by private insurance policies the policy-holder's interest in liberalization must give way to the interests of the public at large. We should consider not only compulsory insurances but also the appointment of beneficiaries in life and accident insurance and the other policies with protective effects in favour of third parties. This lecture, given under the auspices of the Geneva Association, has had but one purpose: to facilitate an open and neighbourly discussion of a subject of great interest to the speaker and, presumably to his audience as well. 